\title{
INFLUENCE OF WORD-OF-MOUTH COMMUNICATION ON LARGE-SCALE EVACUATION AFTER A SEVERE EARTHQUAKE
}

\author{
T. Osaragi ${ }^{1 *}$, T. Tsuchiya ${ }^{1}$ \\ ${ }^{1}$ Tokyo Institute of Technology, 2-12-1 Ookayama, Meguro, Tokyo, Japan - (osaragi.t.aa, tsuchiya.t.ag)@m.titech.ac.jp
}

Commission IV, WG IV/8

KEY WORDS: Large-scale Evacuation, Word-of-mouth Communication, Guide, False Information, Earthquake

\begin{abstract}
:
Physical disaster in a serious earthquake (fires and street blockages), word-of-mouth communication (WOMC) among evacuees, and evacuation behaviors are modeled, and an evacuation behavior simulation is carried out. The influences of WOMC regarding the information about disaster and the locations of evacuation areas on a large-scale evacuation are observed. The simulation results demonstrate some new findings and highlight the importance of providing guides in tourist areas, where there are many people who have limited local geographical information. It is also shown that once false information has appeared in the process of WOMC among the wanderers, especially in locations with a high density of wanderers, the false information will spread quickly among the evacuees by WOMC and can negatively influence a large-scale evacuation.
\end{abstract}

\section{INTRODUCTION}

It is a pressing issue in Japan, one of the most earthquake-prone countries in the world, to establish detailed regional disaster prevention plans envisaging the aftermath of a major earthquake. A wide variety of information must be gathered and incorporated wisely in order to form a plan for a rapid and safe evacuation. For example, information about the locations of evacuation areas, the routes to reach them, street blockage, and related information will be essential to support safe and rapid evacuations. Much potential is seen in the recent and ongoing spread of portable devices as a means of obtaining information about street blockages, fires, and the like, and methods are being explored to make use of social networking services (SNS) to enable real-time reporting, sharing, and reading of such information (Osaragi and Niwa, 2018). However, it is not clear what information is reliable when a large variety and volume of it is flooding in; which is one of the many issues in the use of SNS. There is also the potential for data transmission networks to fail during a serious earthquake. If such networks are disrupted, it will be essential for information about disaster and evacuation support to be transmitted by digital signage and shared directly by the evacuees to each other (word-of-mouth communication, WOMC). On the other hand, there is also much potential for false "information" to be spread by word-of-mouth among evacuees, adding to the difficulties. Thus, it is also necessary to consider the possibility of the creation and dissemination of false information while accounting for the influence of WOMC on large-scale evacuation behaviors, in order to organize a rapid escape to safety.

There is a growing reserve of significant results from studies of evacuation planning that focus specifically on the activities of evacuees. Smyrnakis and Galla (2012) and Henein and White (2010) performed evacuation simulations using cellular automatons that showed a potential for communications to contribute to more efficient and safer evacuation from buildings.
Nuria and Norman (2006) modeled the evacuation of a large group from inside a building and validated the efficacy of WOMC among evacuees, their guides, and other trained personnel regarding evacuation routes. However, these studies were simulations addressing the interiors of buildings and did not address evacuation behaviors over a wide area on a regional scale. Matsuda (2004) investigated advanced Multi-agent Simulation (MAS) incorporating settings for evacuation start times, directions for evacuation, and other parameters in modeling of crowd evacuation. However, his simulation assumed that the evacuees would follow the instructions of the guides and did not model WOMC processes. Aoki et al. (1992) examined WOMC during large-scale evacuation; they constructed a model for evaluating the extent of damage from information evacuees had heard by word of mouth and added this into their simulation to examine the influence of interactions among evacuees on the evacuation. Also, Kimura and Kanoh (2004) incorporated evacuees' characteristics, such as their ages, in WOMC in a MAS model that evaluated a largescale evacuation from the viewpoint of evacuation time. However, they did not consider physical damage or make any observations about evacuation safety.

In the present study, a MAS model was constructed on the basis of the aforementioned reports that describes evacuation behaviors as they vary with physical dam-age following a severe earthquake, WOMC among evacuees and guides, and evacuee types. Evacuation behaviors were simulated and the influence of WOMC in a large-scale evacuation was quantitatively assessed.

\section{MODELING OF VIRTUAL CITY AND EVACUEES}

\subsection{A Virtual City}

The present study analyzes a virtual city modeled referring to an actual region. Unique spatial characteristics of that region

* Corresponding author 
were removed in order to simplify the processes of analysis and interpretation of the influence of WOMC on a large-scale evacuation. The spatial aspects of the virtual city were represented by a simple lattice model. The street widths, nodelink ratio, block sizes, distribution of evacuation areas (in terms of mean evacuation distances) (Figure 1), and other settings were chosen to approximate the actual GIS data from the Setagaya Ward, Tokyo Land Use Survey of FY2011.

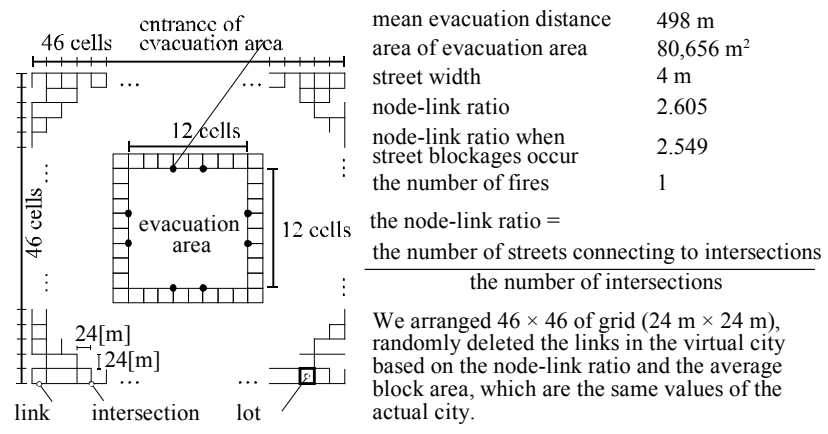

Figure 1. Outline of a virtual city

\subsection{Physical Damage}

The physical damage occurring during a severe earthquake appears in the model as street blockages and breakouts and spread of fire. Street blockages were set randomly throughout the virtual city, using the node-link ratio occurring in the blockages found in a blockage simulation (Hirokawa and Osaragi, 2016) performed using Setagaya Ward. In addition, by using as reference the gross density of fires calculated on the basis of damage predictions made by Tokyo Metropolitan Government (2013), the number of fires breaking out in a hypothetical city was determined, and the locations of fires were set randomly (Osaragi and Oki, 2017) (Figure 2). Avoidance of fires by evacuees in their choice of escape routes was also incorporated (Figure 3).

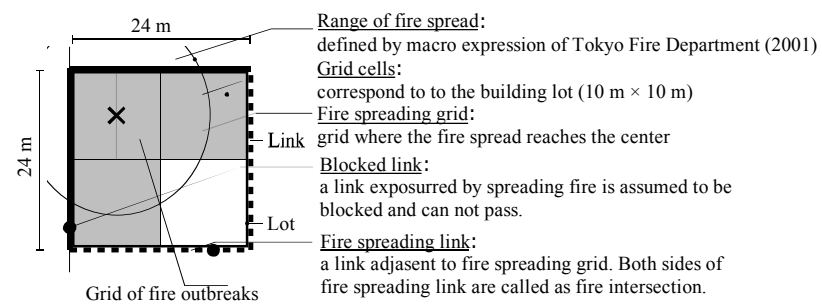

Figure 2. Road damage by spread of fire

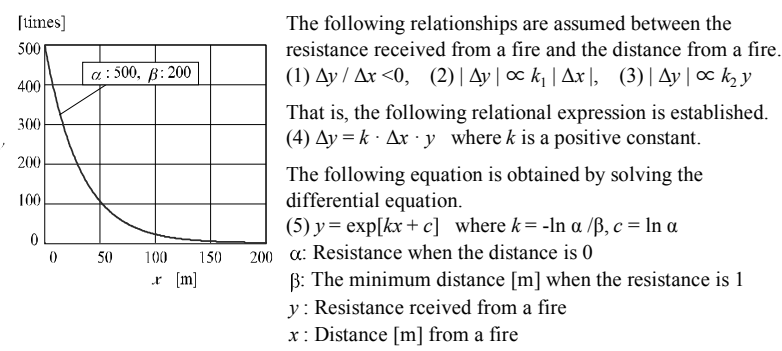

Figure 3. Resistance which evacuees receive from a fire

\subsection{Evacuees}

The behaviors of evacuees as they reacted to WOMC while fleeing to an evacuation area in the virtual city after a serious earthquake were modeled (Figure 4(a)). The final statuses of the evacuees were divided into the following three classes: (i) In shelter: Evacuees who had reached an evacuation area were defined as "evacuees in shelter". (ii) Lost: Evacuees who had gone a considerable distance since evacuation was ordered but were still unable to reach an evacuation area were "lost evacuees". Here, in view of the limits of most people's strength (Osaragi, 2012), people who had walked at least $20 \mathrm{~km}$ but still were outside a shelter were defined as "lost evacuees". (iii) Deceased: Evacuees who had no passable route before or behind them when they reached an intersection and were exposed to fire were defined as "deceased evacuees".

Evacuees will have differing levels of knowledge about their localities, and this will cause them to make different choices for destination and route. The three evacuee types shown in Figure 4(b) were defined on this basis. The "seekers" were those who have no knowledge about their localities, including the roadway network. Other aspects of evacuation are that people will set about fleeing on the basis of (i) straight-line distance to their destination, (ii) initial disaster information, and (iii) information they learn in the roadways that they pass through as they flee. The "efficient evacuees" were those with good knowledge of the roadway network and these took the shortest route to the evacuation area. Between these two groups are the "intermediate evacuees".

Guides (Figure 4(c)), who play the role of leading groups of evacuees, were defined as people familiar with the area who directed evacuees to their destination within a certain timespan. Guides were assumed not to be in shelter, even though they had actually reached an evacuation area.

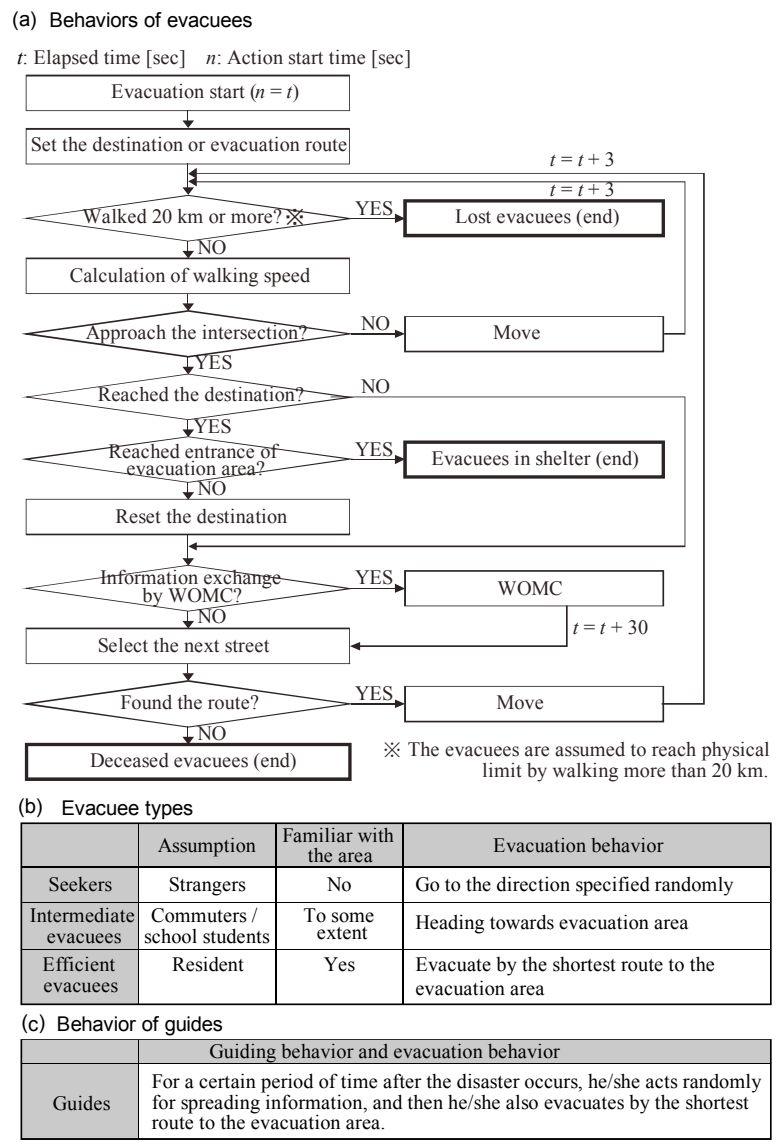

Figure 4. Evacuee types and behaviors of evacuees and guides 


\subsection{Walking Speed}

Walking speed of evacuees drops with increasing density of evacuees and is further reduced if many of the evacuees in the vicinity are going in a different direction. Therefore, a convenient model for expressing this was developed (Figure 5). Evacuee's walking speed was assumed to be influenced by the speed of the evacuees walking in front. Specifically, an evacuee's walking speed was set using the density of other evacuees up to $10 \mathrm{~m}$ ahead according to the relational expression given in Figure 5(a), which incorporates both the case of people walking in the same direction (Osaragi, 2004) and the case of people walking in a different direction (Satoh et al., 2009).

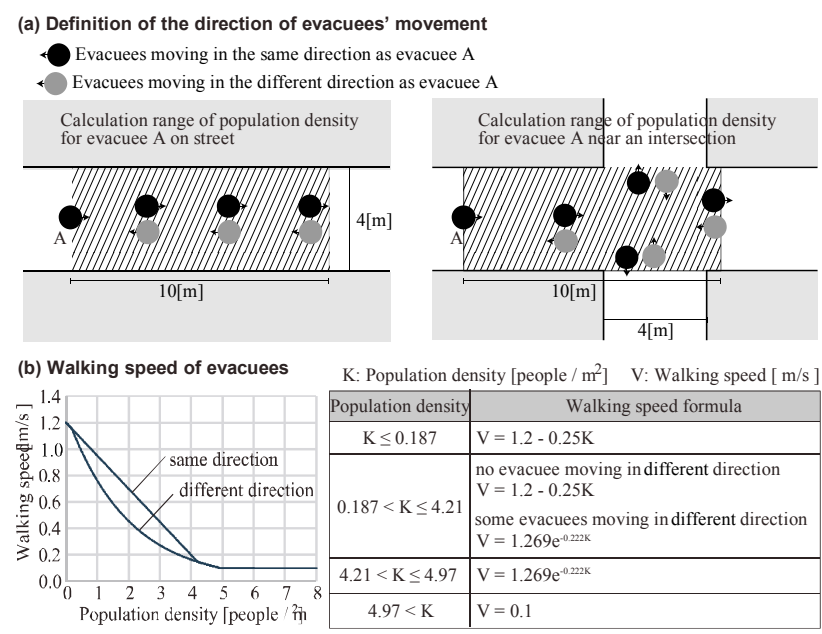

Figure 5. Model of walking speed

\section{CONSTRUCTION OF AN INFORMATION ACQUISITION MODEL}

\subsection{Types of Information}

Evacuees were assumed to exchange information about the location of evacuation areas and about the disaster (i.e., fires and street blockages) as they fled. Here, the information about the disaster was considered to be either visually evident or WOM information. Visually evident information is more reliable than WOM information, so it was assumed that WOM would not be used to update visually available information (Table 1). Furthermore, the range of information available by personally viewing the surroundings differs from the range of WOM information, so these ranges are distinguished in Table 2.

\begin{tabular}{l||l|l|l}
\hline $\begin{array}{l}\text { Types of } \\
\text { disaster } \\
\text { information }\end{array}$ & $\begin{array}{l}\text { Experience of } \\
\text { evacuees }\end{array}$ & $\begin{array}{l}\text { Contents of } \\
\text { transmission } \\
\text { in WOMC }\end{array}$ & $\begin{array}{l}\text { Update of } \\
\text { information } \\
\text { by WOMC }\end{array}$ \\
\hline \hline \multirow{2}{*}{$\begin{array}{l}\text { Visually } \\
\text { evident } \\
\text { information }\end{array}$} & $\begin{array}{l}\text { Had seen a } \\
\text { disaster }\end{array}$ & $\begin{array}{l}\text { "There was a } \\
\text { disaster" }\end{array}$ & $\begin{array}{l}\text { Never } \\
\text { updated by } \\
\text { WOMC }\end{array}$ \\
\cline { 2 - 4 } & $\begin{array}{l}\text { Had seen no } \\
\text { disaster }\end{array}$ & $\begin{array}{l}\text { "There was } \\
\text { no disaster" }\end{array}$ & "There was a \\
\hline \multirow{2}{*}{$\begin{array}{l}\text { WOM } \\
\text { information }\end{array}$} & $\begin{array}{l}\text { Heard there } \\
\text { Was a disaster } \\
\text { disaster" }\end{array}$ & $\begin{array}{l}\text { updated by } \\
\text { WOMC }\end{array}$ \\
\cline { 2 - 3 } & $\begin{array}{l}\text { Heard there } \\
\text { was no disaster }\end{array}$ & $\begin{array}{l}\text { "There was } \\
\text { no disaster" }\end{array}$ & WOMC \\
\hline
\end{tabular}

Table 1. Types of disaster information

\begin{tabular}{l||l|l}
\hline \multirow{2}{*}{ Frequency } & $\begin{array}{l}\text { Visually evident } \\
\text { information }\end{array}$ & WOM information \\
\hline \hline \multirow{4}{*}{$\begin{array}{l}\text { Spatial } \\
\text { range }\end{array}$} & $\begin{array}{l}\text { (i) Fire information: } \\
\text { Collect the fire } \\
\text { information within 50 } \\
\text { meters around the } \\
\text { location of an evacuee. } \\
\text { (ii) Blockage } \\
\text { information: Collect the } \\
\text { blockage information } \\
\text { on streets at the } \\
\text { intersections where } \\
\text { WOMC }\end{array}$ & $\begin{array}{l}\text { Collect for each } \\
\text { information within the } \\
\text { spatial range below. } \\
\text { Spatial range } \\
\text { destination }\end{array}$ \\
\hline
\end{tabular}

Table 2. Frequency and spatial range of disaster information collection

\subsection{Opportunities for WOMC and its Content}

It was not assumed that people always participate in WOMC, but rather that they do so under the circumstances listed in Table 3. It was assumed that WOMC took about 30 seconds and covered information about both the locations of evacuation areas and disaster. We considered that information deemed necessary would vary by evacuee type, and so defined different kinds of information provided by WOM for each evacuee type (Table 4). It was assumed that guides would only provide accurate information, would not accept less reliable information from evacuees by WOMC, and would only accept revisions to information that they possess from what they personally witnessed or by WOM from other guides.

\begin{tabular}{|c|c|}
\hline & Situations that WOMC occurs \\
\hline $\begin{array}{l}\text { Visually } \\
\text { evident } \\
\text { information }\end{array}$ & $\begin{array}{l}\text { When he/she meets seekers or intermediate evacuees } \\
\text { at intersections. }\end{array}$ \\
\hline \multirow[t]{2}{*}{$\begin{array}{l}\text { WOM } \\
\text { information }\end{array}$} & $\begin{array}{l}\text { (1) When he/she encountered evacuees who are } \\
\text { more familiar with the area }\end{array}$ \\
\hline & $\begin{array}{l}\text { (2) When he/she have no choice but to change the } \\
\text { route due to fire or road blockage. }\end{array}$ \\
\hline
\end{tabular}

Table 3. Timing and details of WOMC

\begin{tabular}{l||l}
\hline & \multicolumn{1}{c}{ Types of information obtained by WOMC } \\
\hline \hline \multicolumn{1}{c||}{ Seekers } & Fire information and the location of evacuation area \\
\hline $\begin{array}{l}\text { Intermediate } \\
\text { evacuees }\end{array}$ & Fire information and the location of evacuation area \\
\hline $\begin{array}{l}\text { Efficient } \\
\text { evacuees }\end{array}$ & Fire information \\
\hline Guides & None \\
\hline
\end{tabular}

Table 4. Contents of information obtained by WOMC

\subsection{Methods for Sharing Information by WOMC}

3.3.1 Locations of evacuation areas: Evacuees familiar with the local area possess highly reliable information about the location of the evacuation area; therefore, the other evacuees were assumed to follow the instructions of the evacuee with the most reliable knowledge (Figure 6(a)). 
3.3.2 WOMC about disaster information: A model of evacuees' assessments of disaster information was constructed (Figure 6(b)) in order to model WOMC regarding the disaster situation, which can change from one moment to the next. Specifically, each evacuee was assumed to evaluate whether a situation was dangerous according to the model shown in Figure 6(c) on the basis of the number of evacuees within the evacuees' range of acquisition of information (Figure 6(b)) who claimed that there was or was not danger.

(a) WOMC model (location information of the evacuation area)

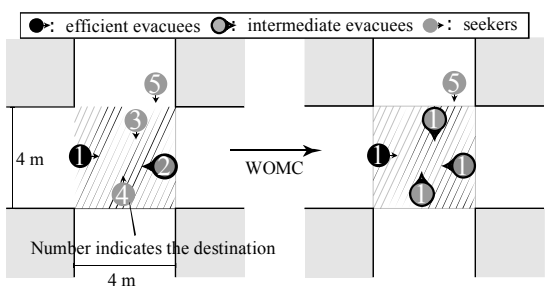

Evacuees familiar with the local area possess highly reliable information about th location of the evacuation area. If there are multiple evacuees of the same type, one of hem is randomly chosen. If there is efficient evacuees, seekers and intermediate evacuees are assumed to follow efficient evacuees.

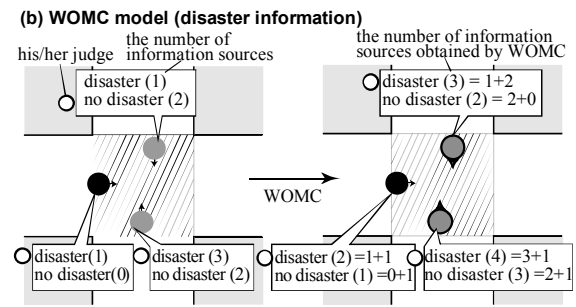

Evacuees are assumed to a cquire and hold the number of information sources of disasters by WOMC. The information provided by the guids is assumed to be equivalen information judgment, the disaster information judgment model shown in (c) is used.

(c) Disaster information judgment model
\begin{tabular}{|l|l|}
\hline & \multicolumn{1}{|c|}{ Judgement } \\
\hline $\mathrm{n}_{1} / \mathrm{n}_{2}<1$ & Judge that there is not danger \\
\hline $\mathrm{n}_{1} / \mathrm{n}_{2}>1$ & Judge that there is danger \\
\hline $\mathrm{n}_{1} / \mathrm{n}_{2}=1$ & Judge randomly that there is danger $/$ not danger \\
\hline
\end{tabular}
$\mathrm{n}_{1}:$ The number of information sources claiming that there is danger
$\mathrm{n}_{2}:$ The number of information sources claiming that there is not danger

Figure 6. Model of WOMC

\subsection{Shifts in Evacuee Type due to Information Acquisition}

The evacuees' knowledge of their local area will be expanded and improved by the information (about the location of the evacuation area) they gain through WOMC. Accordingly, changes in an individual's evacuee type due to information gained (changes in pattern of evacuation behaviors) were modeled (Figure 7).

\section{(a) Transition of evacuee type by WOMC}

Since geographical information can not be perfectly grasped with just WOMC, the seekers will be assumed to transit to the intermediate evacuees.

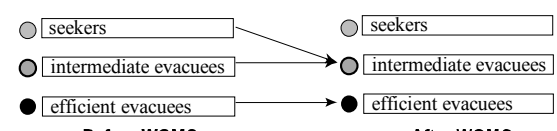

Before WOMC After woMc

(b) Transition of evacuee type by information bulletin board

An information bulletin board was installed at an intersection within one block from the evacuation area. Since it is easy to grasp the location of evacuation area by the bulletin board, all the evacuees will be transit to the efficient evacuees.

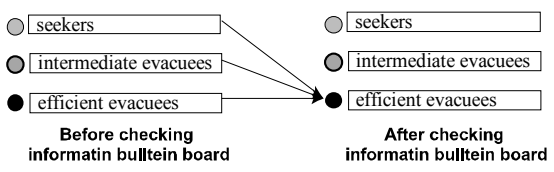

Figure 7. Transition of evacuee types after information acquisition

\section{EFFECTIVENESS OF WORD-OF-MOUTH COMMUNICATION}

\subsection{Method of Assessment of Simulation}

A large-scale evacuation simulation was carried out under the conditions shown in Figure 8. In this analysis, a large-scale evacuation is assessed for several parameters; in addition to the evacuation time and frequency of WOMC, the risk to evacuees involved in an evacuation is examined (Table 5) using the time spent in evacuation walking along roadways that are dangerous due to exposure to fires (risk exposure time).

(a) Conditions of simulation

\begin{tabular}{|l|l|}
\hline Total number of evacuees & 20,000 people \\
\hline Evacuation start time & $\begin{array}{l}\text { Poisson distribution } \\
\text { or when fire approaches }\end{array}$ \\
\hline Time of disaster occurrence & 6:00 p.m. in Winter \\
\hline Weather conditions & Wind velocity $0 \mathrm{~m} / \mathrm{s}$ \\
\hline Number of fire & 1 \\
\hline Number of trials & 10 \\
\hline
\end{tabular}

The total number of evacuees was set by reference to population density $\left(15,102\right.$ people $\left./ \mathrm{km}^{2}\right)$ in Setagay

Ward, Tokyo. The Poisson distribution $(\lambda=3.35)$ is use for the evacuation start time. Evacuation is assumed to be initiated at the time the link with evacuees becomes a fire spreading link.

(b) Evacuation start time

Figure 8. Conditions of simulation

\begin{tabular}{|c|c|}
\hline $\begin{array}{l}\text { Evacuation } \\
\text { time }\end{array}$ & $\begin{array}{l}\text { Time from the time the evacuees started to move } \\
\text { to the time they reach the evacuation area }\end{array}$ \\
\hline $\begin{array}{l}\text { Risk exposure } \\
\text { time }\end{array}$ & $\begin{array}{l}\text { Time when evacuees passed the danger link (link } \\
\text { within } 200 \mathrm{~m} \text { from fire) during evacuation }\end{array}$ \\
\hline $\begin{array}{l}\text { Frequency of } \\
\text { WOMC }\end{array}$ & $\begin{array}{l}\text { Number of times evacuees conducted WOMC } \\
\text { during evacuation }\end{array}$ \\
\hline $\begin{array}{l}\text { Number of lost } \\
\text { evacuees }\end{array}$ & $\begin{array}{l}\text { Evacuees who cannot complete evacuation even if } \\
\text { walking more than } 20 \mathrm{~km} \text { from the beginning of } \\
\text { evacuation. Define them as lost evacuees (people } \\
\text { with evacuation difficulty). They are excluded } \\
\text { from the calculation of the evacuation time, risk } \\
\text { exposure time, frequency of WOMC. }\end{array}$ \\
\hline
\end{tabular}

Table 5. Evaluation method

\subsection{Method of Assessment of Simulation}

Simulations were conducted using extreme values for the fractions of the evacuee types in the virtual city (Figure 9(a)) in order to examine the influence of WOMC on each evacuee type in terms of their evacuation behaviors.

In a virtual city with a majority of seekers (tourist area), the evacuation time and risk actually increased when we employed WOMC as a parameter (Figures 9(c) and (d)). Seekers will engage in WOMC to learn the locations of evacuation areas (Figure 9(b)), but when everyone around one is another seeker, unreliable "information" is passed around by WOMC, and one cannot obtain accurate information about the locations of regional evacuation areas. Conversely, in a virtual city with a majority of efficient evacuees (residential area), all evacuees have accurate information about the locations of evacuation areas, and flee to these sites with almost no WOMC (Figure 9(b)). Thus, there was not much difference in evacuation time or risk even if WOMC was considered (Figures 9(c) and (d)). 


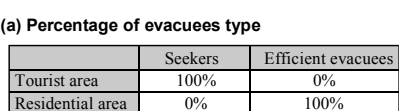

(b) Average frequency of WOMC
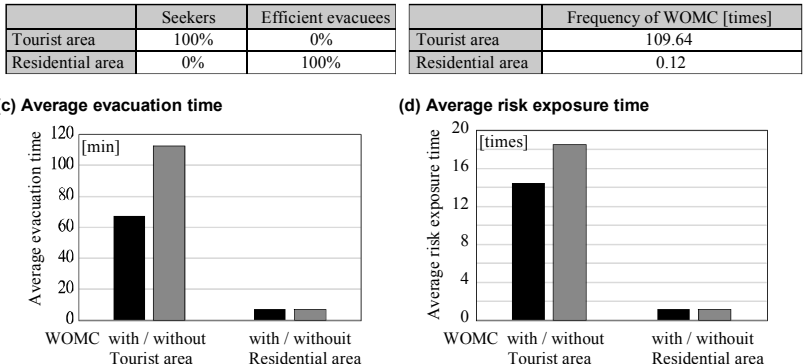

(d) Average risk exposure time

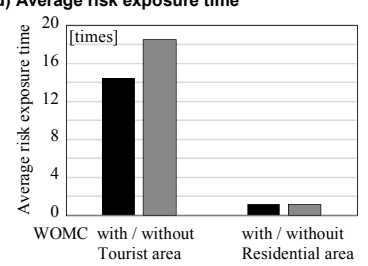

Figure 9. Influence of WOMC in each virtual city type

\subsection{Effectiveness of WOMC Regarding Information about the Locations of Evacuation Areas}

Generally, some fraction of the population of a tourist area comprises efficient evacuees (tourist guides who know the area and local residents) with accurate information about the locations of evacuation areas. Therefore, an analysis was conducted while varying the fraction of efficient evacuees to determine their influence. As this fraction was increased, the evacuation time and risk for the seekers fell (Figures 10(a) and (b)) and the number of evacuees who were lost also fell (Figure 10(c)). For example, the reader can see that increasing the fraction of efficient evacuees to just $0.2 \%$ reduced the evacuation time and risk of seekers by half. The frequency of WOMC for the seekers was also reduced, indicating that the information exchanged was of higher reliability, enabling the evacuees to reach the evacuation areas with fewer questions (Figure 10(d)).

The above results indicate that even when the region population is mainly made up of people who are unfamiliar with the region, the presence of a minority who have accurate information has the potential to allow the dissemination of the information needed for evacuation by WOMC, effecting an efficient evacuation.

\section{VALIDATION OF EFFECTIVENESS OF WORD-OF- MOUTH COMMUNICATION}

\subsection{Influence of Variation in Ratio of Guides}

The results presented in the previous section demonstrated that dissemination of highly reliable information by local residents and other efficient evacuees will be effective for assisting people unfamiliar with an area to find the nearest regional evacuation area. However, since the efficient evacuees reached an evacuation area within about 10 minutes, they did not run into seekers very often. Therefore, we examined how effective it would be to introduce guides with the role of disseminating information for some set period of time. A simulation was performed under the conditions shown in Figure 8. When guides were present who can provide accurate information about the locations of evacuation areas, the evacuation time and risk for seekers are greatly decreased from when only efficient evacuees with no formal responsibility to provide guidance are present (Figures 11(a) and (b)). Moreover, the addition of guides as even just $0.1 \%$ of the population greatly decreased the number of lost evacuees (Figure 11(c)). The essential finding here is that the seekers did not have very many conversations directly with the guides (Figure 11(d)). Instead, accurate information from guides about the locations of evacuation areas was disseminated to the seekers by repeated WOMC, thereby increasing the efficiency of the evacuation.
Conditions of simulation

Virtual city type $=$ Tourist area (Seekers + Efficient evacuees) (a) Average evacuation time

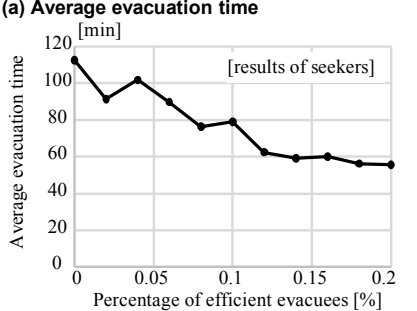

(c) Number of lost evacuees

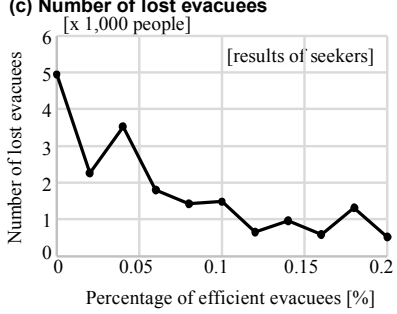

(b) Average Risk Exposure Time

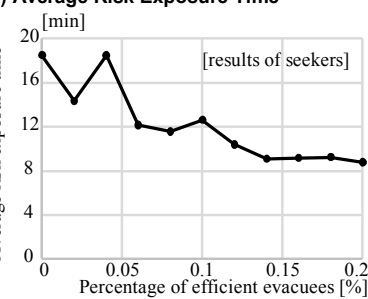

(d) Average frequency of WOMC

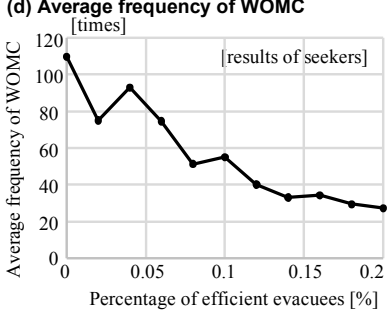

Figure 10. Effects of WOMC about the location of evacuation area

Conditions of simulation $/$ Virtual city type $=$ Tourist area

Start time of guide $=$ immediately after disaster occurs $/$ Guide time $=14$ hours

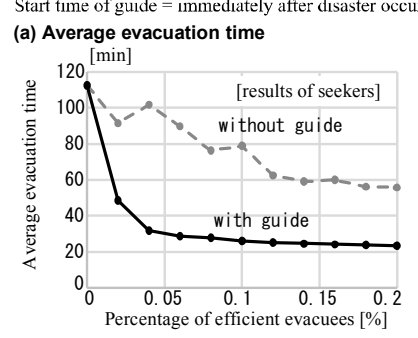

(b) Average Risk Exposure Time
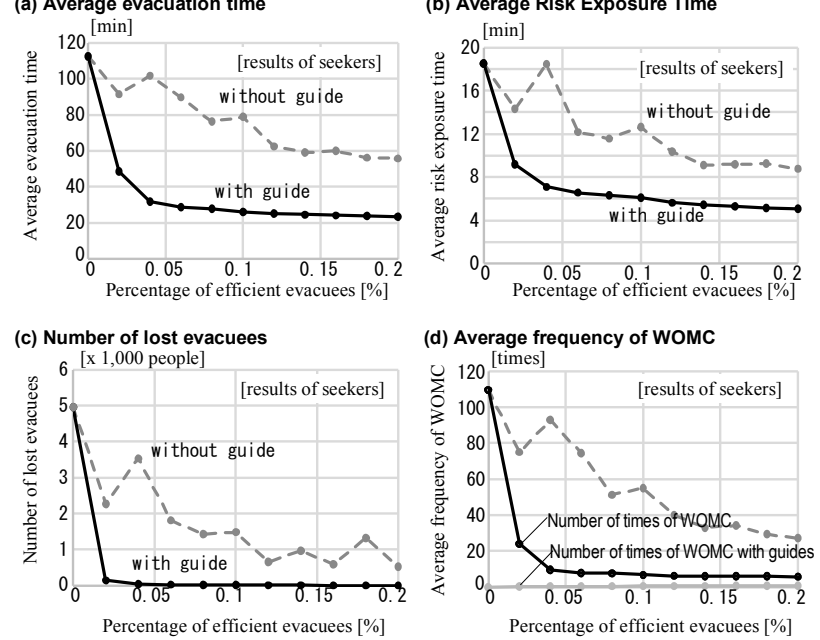

(d) Average frequency of WOMC

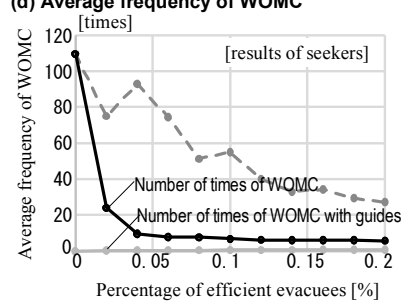

Figure 11. Effects of WOMC with guides

\subsection{Influence of Variations in Time Instructions are Available}

In the analysis of the previous section, the timespan for making guides available to give directions was set at 14 hours, but it is also essential to consider the physical demand on the guides. The investigation employed a fraction of guides of $0.1 \%$ (Figure 12) and examined the effect of varying the availability time on a large-scale evacuation. We can see that the evacuation time and risk to seekers were considerably reduced by the availability of guides from immediately after the earthquake for even 2 hours (Figures 12(a) and (b)) and that the number of lost evacuees was greatly reduced (Figure 12(c)). Also, the fact that there were not many direct communications with guides shows that WOMC was quite frequent among the seekers (Figure 12(d)). The information disseminated among the evacuees due to WOMC was more accurate even after guidance from the guides had ceased (more than 2 hours after the earthquake). The spatial distribution of evacuees with the information of evacuation area is shown in Figure 13. 
Conditions of simulation $/$ Virtual city type $=$ Tourist area (Seckers: $99.9 \%$, Guides: $0.1 \%$ ) Start time of guide $=$ immediately after disaster occurs
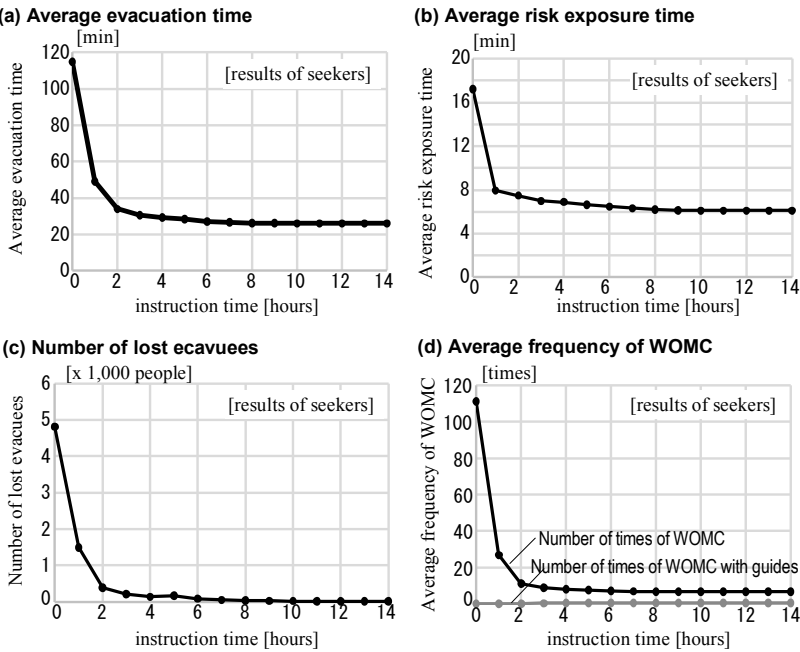

Figure 12. Effects of instruction time
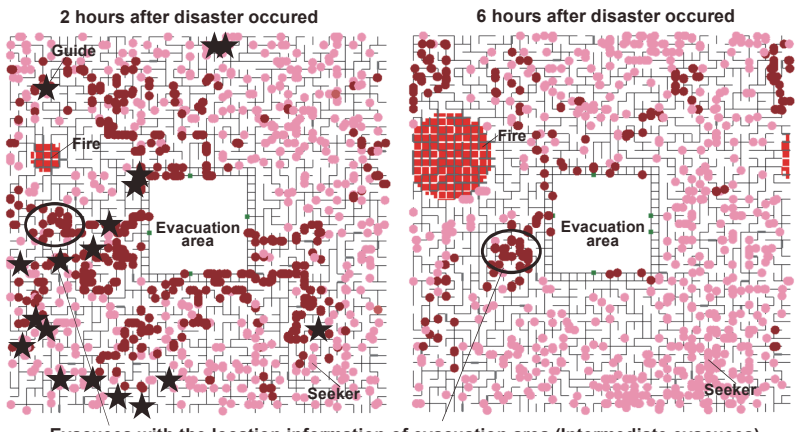

Figure 13. Spatial distribution of the location information of evacuation area

\subsection{Influence of Variations in Method of Guidance}

Three types of guides were considered to correspond to the various ways in which information about disaster can be gathered (independent guide, cooperating guide, almighty guide) (Figure 14), and the influence of differences between those methods was examined. There were no dramatic differences in evacuation time and frequency of WOMC for the seekers by guide type (Figures 14(a) and (c)). However, cooperating guides are more capable, though not much more, of reducing the risk to seekers than independent guides (Figure 14(b)). Cooperation by guides also reduces the risks to guides themselves (Figure 14(d)). This is because the information held by the independent guides becomes outdated over time; by sharing information with other guides, they are able to keep abreast of the latest regional information.

\section{INFLUENCE OF FALSE INFORMATION}

\subsection{Modeling False Information}

Due to false rumors and assumptions, much false information may be disseminated along with the accurate information in the confusion following a disaster. Even accurate information can be garbled with repetition in the initial WOMC and become false. The process of commingling of false information with the truth was modeled and incorporated in the simulation to investigate the influence of this on a large-scale evacuation.
Conditions of simulation $/$ Virtual city type $=$ Tourist area $($ Seekers: $99.9 \%$, Guides: $0.1 \%)$ Start time of guide $=$ immediately after disaster occurs

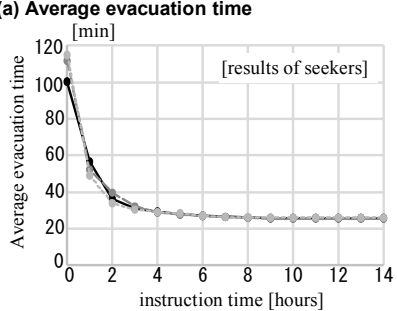

(c) Average frequency of WOMC

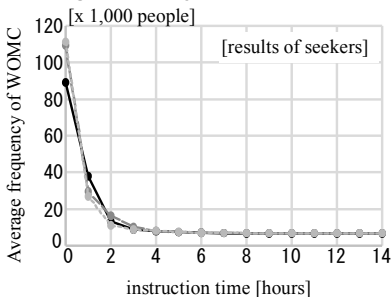

instruction time [hours] (a) Average evacuation time (b) Average risk exposure time

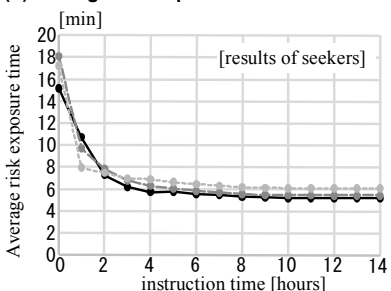

(d) Average risk exposure time

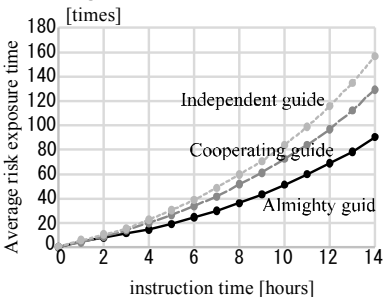

\section{[Method of guidance]}

Independent guide (Collecting information by his/herself)

Cooperating guide (Sharing information among the guides) ----
Almighty guide (Having all necessary information)

Figure 14. Influence of variations in method of guidance

We herein assumed that misinformation (the passing on of information that is actually false) occurs a certain percentage of the time in regard to disaster information in WOMC among evacuees. Specifically, in order to visualize the process of misinformation, the numbers of people providing information shown in Figure 6 were inter-changed (Figure 15). As before, the information provided in WOMC by guides was assumed to be $100 \%$ accurate. Below, in addition to the evaluation indicators for evacuation time and risk exposure time, the fraction of misinformed evacuees, an indicator of the degree of dissemination of false information, is examined.

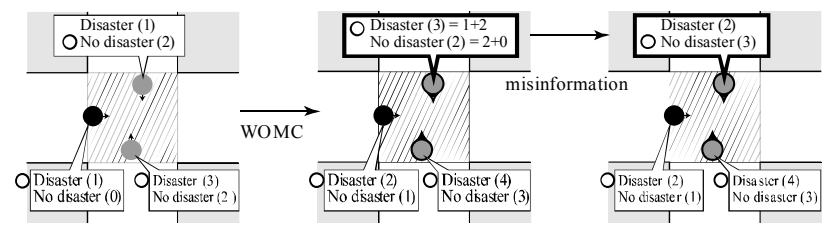

Figure 15. Model of false information generation

\subsection{Influence of Misinformation on a Large-scale Evacuation}

The incidence of misinformation was varied under conditions promoting efficient evacuation of seekers (Figure 16) to observe the effect of this parameter on a large-scale evacuation. In the case of a low incidence of misinformation, there was little difference in evacuation time and risk from the case in which misinformation was assumed not to occur (Figures 16(a) and (b)). However, these parameters showed an exponential rise as the incidence of misinformation was increased. For example, when the incidence was raised to the still low level of $0.1 \%$, the evacuation time and risk due to the false information disseminated by WOMC (Figure 16(d)) doubled relative to when zero misinformation was assumed (Figures 16(a) and (b)). It is quite clear that once false information has appeared, many evacuees find themselves unable to locate a regional evacuation area and spend much time wandering about the streets (Figure 15(c)). Moreover, as more and more evacuees appear on the streets over time, they have increasing frequency of WOMC, 
exacerbating the generation and spread of false information. When the incidence of misinformation in WOMC was increased to $1.0 \%$, approximately $70 \%$ of the evacuees were misinformed at 2 hours after the earthquake (Figure 16(d)). This resulted in a persistent high fraction of misinformed evacuees after the earthquake. Examining the spatial distribution of the false information in the blocks (mesh) (Figure 17), we see that it had spread throughout the city within 1 hour after the earthquake; at that time, the maximum number of evacuees per block who were misinformed was low, only 20 . However, 3 hours after the earthquake, this had swollen to the much higher maximum of 470 people per block; false information was particularly widespread about the neighborhood of the evacuation area. The neighborhood of the evacuation area is a topic of critical importance to many evacuees and was often exchanged, so once false information had appeared, it tended to remain for a long time.

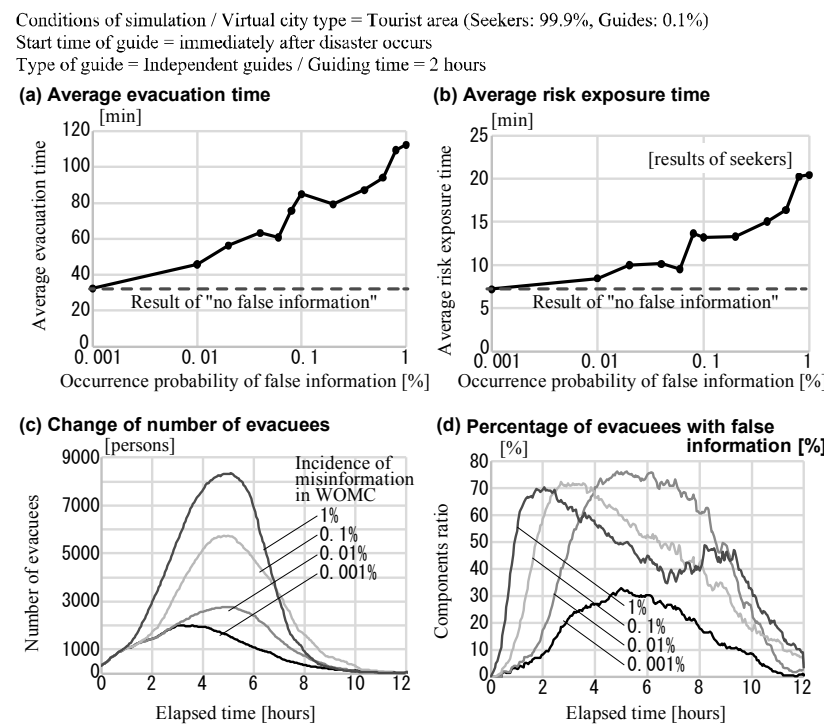

Figure 16. Influence of misinformation spreading

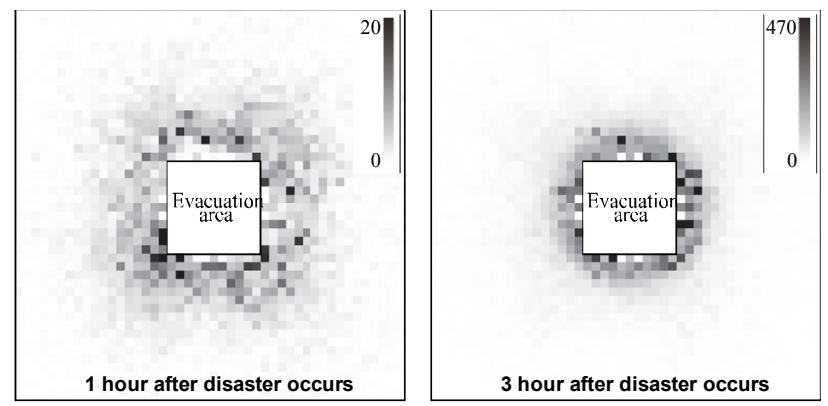

Spatial distribution of evacuees with false information (fire information) (Incidence of misinformation in $\mathrm{WOMC}=1.0 \%$ )

Figure 17. Influence of false information spreading

The results of the above analysis clearly indicate that once false information that is needed by many evacuees has been generated and disseminated, it will negatively affect evacuees in large-scale evacuation.

\subsection{Influence from Differences in Population Density}

The dissemination of disaster information is dependent upon the frequency of WOMC. In other words, the speed of spread of information is strongly dependent on population density. Accordingly, the simulation conditions presented in Figure 16 were used to vary the population density of the virtual city and the influence of this was investigated. The results are given in Figure 18.

Conditions of simulation / Virtual city type $=$ Tourist area (Seekers: $99.9 \%$, Guides: $0.1 \%$ ) Start time of guide $=$ immediately after disaster occurs $/$ Type of guide $=$ Independent guides Guiding time $=2$ hours $/$ Incidence of misinformation in $\mathrm{WOMC}=1.0 \%$

(a) Average evacuation time

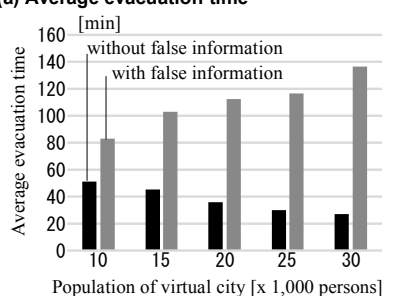

(b) Average risk exposure time ${ }_{30}^{[\mathrm{min}]}$

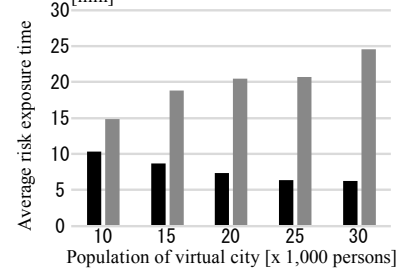

(c) Average frequency of WOMC

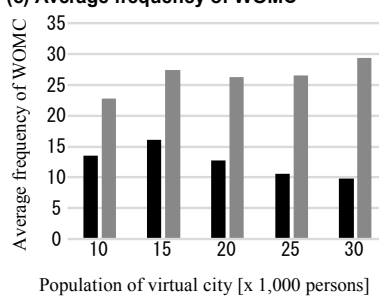

(d) Average frequency of WOMC with guides
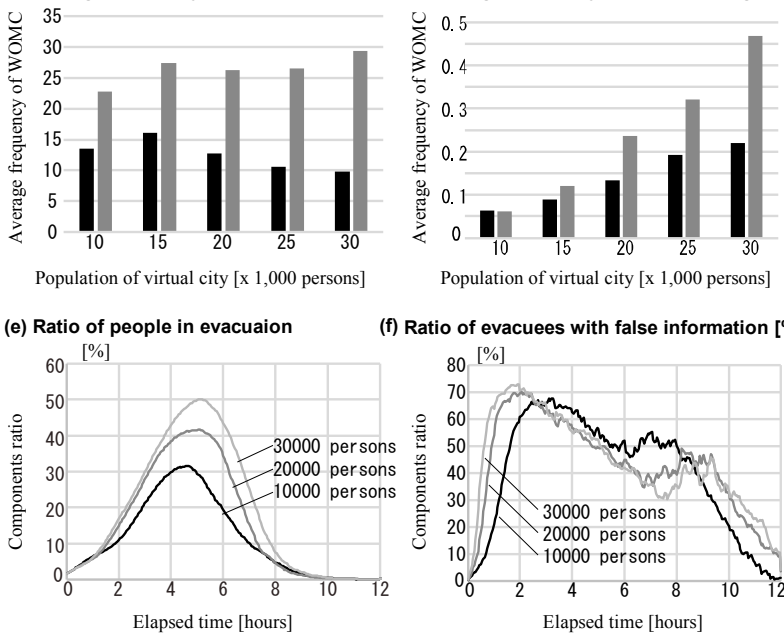

(f) Ratio of evacuees with false information [\%]

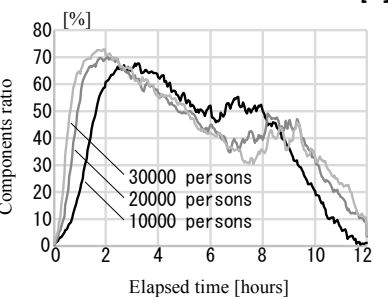

Figure 18. Influence of population density on dissemination of disaster information

As long as no false information appears in a city with a high population density, it is easy for accurate information to be disseminated. The evacuation time will then be short and the risk will be low (Figures 18(a) and (b)). Once false information has appeared and spread by WOMC, however, it becomes very difficult to accomplish a rapid and safe evacuation, and the evacuation time and risk increase (Figures 18(a) and (b)). This is due to the following factors. When the population density is high, there are more people evacuating at the same time (Figure 18(e)); this increases the frequency with which evacuees meet each other, and accordingly, the frequency of their WOMC (Figure 18(c)). They also run into guides who provide accurate information more often (Figure 18(d)). However, if we focus on the fraction of misinformed evacuees, we see that this fraction climbed sharply immediately after the earthquake struck in a city with a high population density (Figure 18(f)). This seems likely to have occurred because even though the false information is corrected upon communicating with a guide, this correction is outstripped by the speed of WOMC among evacuees themselves.

The above results indicate that disaster information can be disseminated rapidly in a city with a high population density; this is advantageous to evacuation when the information is correct, but when false information appears, it spreads quickly among the evacuees by WOMC and can negatively influence a large-scale evacuation. 


\section{INFLUENCE OF FALSE INFORMATION}

Physical disaster in a serious earthquake (fires and street blockages), WOMC among evacuees, and evacuation behaviors were modeled, and an evacuation behavior simulation was carried out for a virtual city. The influences of WOMC regarding the information about the locations of evacuation areas and disaster on a large-scale evacuation were observed.

First, the simulation in which the behaviors of evacuee types and guides were modeled and demonstrated produced the following findings: (1) In a region where the majority of the population has little knowledge of the local area, few evacuees have accurate information about the locations of evacuation areas, so people will obtain little effective information by WOMC. Information of little reliability will be disseminated repeatedly. As a result, evacuation times and risk are potentially large. (2) If guides with much knowledge of the local area begin providing directions for evacuation immediately after a disaster, correct information is disseminated among the evacuees by WOMC, and the evacuation time and risk can be greatly reduced. (3) If guides share information with each other, they will always be able to provide directions based on the latest information about the region as a whole, and this can reduce the risk not only to the evacuees but also to the guides themselves.

The following findings were also revealed by the simulation modeling the processes of appearance and dissemination of misinformation: (i) False information about the neighborhood of an evacuation area, which is needed by many evacuees, may be increasingly disseminated as the incidence of misinformation increases, which can negatively affect a large-scale evacuation. (ii) Accurate information spreads quickly by WOMC in a city with a high population, and this aids the efficiency of evacuation. When misinformation appears along with accurate information, however, the misinformation is disseminated rapidly just after the disaster and can negatively affect the evacuation time and risk of evacuees.

The above results highlight the importance of providing guides in tourist areas, where there are many people who have limited local geographical information. Ways must be found to provide information that aids safe and efficient evacuations. Once false information has appeared in the process of WOMC among the wanderers, especially in locations with a high density of wanderers, the false information will spread, and it is necessary to study ways to suppress its dissemination.

\section{ACKNOWLEDGEMENTS}

This paper is a part of the research outcomes funded by Core Research for Evolutionary Science and Technology (CREST) and Japan Science and Technology Agency (JST). A portion of this paper was published in the Journal of Architectural Planning and Engineering, in an article entitled "Influence of Information-hearsay on Wide-area Evacuation Immediately after a Large Earthquake", 82 (739), pp.2325-2333, 2017 (in Japanese).

\section{REFERENCES}

Aoki, Y., Osaragi, T., Hashimoto, K., 1992. A Simulation Model of Evacuation Behavior in the Fire-Spread Urban Area following Earthquake, Transactions of AIJ. Journal of architecture, planning and environmental engineering, 440: 111-118. (in Japanese)
Henein, C. M., White, T., 2010. Microscopie information processing and communication in crowd dynamics, Physica A, $389,4636-4653$.

Hirokawa, N., Osaragi, T., 2016. Earthquake Disaster Simulation System: Integration of Models for Building Collapse, Road Blockage, and Fire Spread, Journal of Disaster Research (Special Issue on Disaster and Big Data), Fuji Technology Press Ltd., 11(2):175-187

Kimura, Y., Kanoh, H. 2004. The Effectiveness of Communication on Wide Area Simulation of Disaster Evacuation Using Multiagent Model, IPSJ SIG technical reports, 69-72. (in Japanese)

Matsuda Y., 2004. A study on simulation of evacuation behavior considering beginning time of evacuation and the influence of leader during evacuation, In: Summaries of technical papers of Annual Meeting Architectural Institute of Japan. A-2, Fire safety, off-shore engineering and architecture, information systems technology, 243-244. (in Japanese)

Nuria, P., Norman, I. B., 2006. Modeling crowd and trained leader behavior during building evacuation, IEEE Computer Graphics and Applications, 26(6):80-86.

Osaragi, T., 2004. Modeling of Pedestrian Behavior and Its Applications to Spatial Evaluation, In: Proceedings of Third International Joint Conference on Autonomous Agents and Multiagents Systems, Proceedings of the Third International Joint Conference on Autonomous Agents \& Multi Agent Systems (AAMAS'04) 2: 834-841.

Osaragi, T., 2012. Modeling a spatiotemporal distribution of stranded people returning home on foot in the aftermath of a large-scale earthquake, Natural Hazards, Springer, Springer Netherlands, 68(3): 1385-1398.

Osaragi, T., Niwa, I., 2018. Development of System for Realtime Collection, Sharing, and Use of Disaster Information, A. Mansourian et al. (eds.), Geospatial Technologies for All, Lecture Notes in Geoinformation and Cartography, 1-19.

Osaragi, T., Oki, T., 2017. Wide-Area Evacuation Simulation Incorporating Rescue and Firefighting by Local Residents, Journal of Disaster Research (Special Issue on Disaster and Big Data), Fuji Technology Press Ltd., 12(2): 296-310.

Satoh. K., Takahashi, T., Yamada, T., Terano, T., 2009. Study on Emergent Behaviors of Crowded People in a Station through an Agent-based Simulation Model, SIG Technical Reports, 8186. (in Japanese)

Smyrnakis, M., Galla, T., 2012. Effects of communication and utility-based decision making in a simple model of evacuation, Eur. Phys. J. B, 85: 378.

Tokyo Metropolitan Government, 2013. http://www.bousai.metro.tokyo.jp/_res/projects/default_project/ page $/ 001 / 000 / 401 /$ assumption_h 24 outline.pdf [accessed Mar. $15,2018]$ (in Japanese) 